\title{
Therapeutic Applications of Scorpion Venom in Cancer: Mini Review
}

\author{
Ghulam Nabi (Corresponding author) \\ M.Phil. Scholar. Animal sciences Department \\ Reproductive neuro-endocrinology Lab. Quaid-i-Azam University, Islamabad, Pakistan \\ Tel: 92-345-811-2741Ｅ-mail: ghulamnabiqau@gmail.com
}

Naveed Ahmad

M.Phil. Scholar, Department of Pharmacy, University of Malakand, Pakistan

Tel: 92-346-984-0340Ｅ-mail: naveed_pharmacist@yahoo.com

Sana Ullah

M.Phil. Scholar. Animal sciences Department. Quaid-i-Azam University, Islamabad, Pakistan

Tel: 92-346-898-1437Ｅ-mail: sunyuop@gmail.com

Ghufran

M.Phil. Scholar, Department of Pharmacology, Khyber Medical University Peshawar, Pakistan Tel: 92-345-937-1583Ｅ-mail: dr.ghufran2012@gmail.com

\begin{abstract}
Sikandar Khan
M.Phil scholar, Department of chemistry, University of Malakand, Pakistan.

E-mail: sikandarkhan590@yahoo.com
\end{abstract}

Received: October 10, 2014 Accepted: October 21, 2014

doi:10.5296/jbls.v6i1.6418 URL: http://dx.doi.org/10.5296/jbls.v6i1.6418 


\section{Abstract}

The scorpion venom is a potential therapeutic biological source against a variety of diseases. Scorpion venom contained low molecular weight peptides, salts, different enzymes and neurotoxins. These peptides have immunosuppressive, cytotoxic, apoptogenic and anti-proliferative effects. These activities make scorpion venom a novel therapeutic agent against a variety of cancers like human lung adenocarcinomas, prostate cancer, melanoma, breast cancer, brain tumors, gliomas, leukemia, skin cancer, cervical cancer, esophageal cancer and colon cancer. This review focuses on scorpion venom and its applications for various types of cancers.

Keywords: Scorpion, Venom, Cancer

\section{Introduction}

Scorpions are most primitive arthropods belonging to order scorpiones and class Arachnida (Ruming et al., 2010). They are classified into 18 families and about 1500 different species and subspecies (Bawaskar and Bawaskar, 2012. The most fatal and medically important scorpions belong to Buthidae family (Michael, 2003). Scorpion body is divided into three parts: the head (cephalothorax), the abdomen (mesosoma) and the tail (metasoma). Except in Antarctica, scorpions are found in all continents and in subtropical and tropical regions cause severe problems (Ruming et al., 2010). On this planet, scorpions are one of the primitive creatures. The existence of scorpions dates back to more than 400 million years. At the end of the scorpion telson, there is specialized venom gland that produces toxin loaded with venoms. Scorpions capture their prey and defend themselves from predators via secretions of these venoms (Posani et al., 1999; Jeyaprakash et al., 2009).

\section{Habitats}

Scorpions, except in Antarctica are present in all continents and causes serious problems in subtropical and tropical regions. They are adapted to survive in a wide variety of habitats including caves, temperate forests, savanna, grasslands, rain forests, snow covered mountains and tropical forests (Dehesa-Dávila et al., 1994; Ruming et al., 2010).).

\section{Composition of Scorpion venoms}

Scorpion venoms are very complex mixtures with hundreds of different components such as, mucosa, oligopeptides, nucleotides, amino acids, ions, neurotransmitters, salts, unidentified substances, water and low molecular weight peptides (Possini et al., 1999). It also includes enzymes such as phospholipase, hyaluronidase, lipase, alkaline phosphotases and proteolytic enzymes (Park et al., 2007). It has been suggested that in the 1500 distinct species of scorpions around the world, 100000 different peptides exist, of which only $0.02 \%$ are known to interact with ion channels (Possani et al., 2000).

\section{Classification of Scorpion Venom}

The scorpion venom peptides are generally classified into two main groups: the disulfide bridged peptides (DBPs) which usually target membrane bound ion channels and the 
non-disulfide-bridged peptides (NDBPs), a smaller group within the scorpion venom peptide arsenal, that display multifunctional activities. Most scorpion DBPs contain three to four disulfide bridges and are further sub-classified into four different families according the type of membrane channels they interact with. The membrane bound ion channels targeted by the DBPs family of scorpion peptides include the $\mathrm{Na}+, \mathrm{K}+, \mathrm{Ca} 2+$ and $\mathrm{Cl}-$ channels. These channels play major roles in regulating the normal cellular physiology within many mammalian organisms and disrupting the function of these channels by interacting with scorpion venom peptides can result in significant alterations in their normal function, leading to the several symptoms developed in mammals during scorpion envenomation. NDBPs have several biological functions such as, anticancer, anti-inflammatory, antimicrobial, hemolytic, bradykinin potentiating and immune-modulatory activities (Ammar and Qosay, 2014). Scorpion toxins are classified on the basis of mode of action, chemical structure and binding site on different channels or channel subtypes. Each class consists of several peptides isolated from the venom of different species of scorpion and are based on their pharmacological action and also agrees well with the structural properties of this peptide family. The long-chain toxins affecting sodium channels have been subdivided primarily into two major subtypes, $\alpha$ and $\beta$-toxins (Possani et al., 2000).

\subsection{Scorpion $\alpha$-Toxins}

In vertebrates, $\alpha$-toxins bind to $\mathrm{Na}^{+}$channels. $\alpha$ toxin abruptly inactivate sodium channels receptor affinity and induces prolongation of the action potential of muscles and nerves (Catterall, 1992).

\subsection{Scorpion $\beta$-Toxins}

From American scorpions, $\beta$-toxins are isolated. In vertebrates, $\beta$-toxins binds to $\mathrm{Na}^{+}$channels on receptor site 4 , allowing a sudden shift to a more negative membrane potential. CssIV is a $\beta$-scorpion toxin isolated from Centruroides suffussus scorpion venom binds to sodium channel. Toxin Ts 1 also called Ts $\gamma$, obtained from the venom of Brazilian scorpion Tityus serrulatus. Based on the site of actions, competitive binding assay and its structural homology, this toxin is also considered as $\beta$-scorpion toxin (Cestèle and Catterall, 2000).

\subsection{Sodium Channels Toxins (NaTx)}

For generation and propagation of action potentials initiation, voltage-gated sodium channels are critical. Several neurotoxins target these channels by bindings to several receptor sites on the pore-forming $\alpha$-subunit. Scorpion toxin in mammals and insects has preference for distinct sodium channels subtypes (Yu and Catterall, 2003).

\subsection{Potassium Channels Toxins (KTx)}

Potassium channels have major roles in various biological processes as well as involved in an increasing number of human pathologies. Various potassium channel blockers are used for the treatment of a number of human diseases such as, cancer, inflammatory neuropathies and autoimmune disorders. Scorpion toxins that target $\mathrm{K}^{+}$channels (KTx) are short-chain peptides cross-linked by three or four disulfide bridges. The $\alpha$-KTx family constitutes by more than 50 
different $\alpha$-KTx have been reported and listed in more than 18 families. Tenenholz et al., 2000 described that $\alpha / \beta$ scaffold formed by an $\alpha$-helix and a two- or three-stranted $\beta$-sheet linked by two bridges. However the $\alpha / \beta$ fold is shared by a variety of polypeptides with diverse functions, such as toxins active on $\mathrm{Na}^{+}$channels. Several studies have described that, neurotoxin $\alpha$-KTx 12.1 also called TsTX-IV, isolated from $T$. serrulatus venom has four disulfide-bridged. The voltage-gated potassium channel has a role in immune responsiveness. Delayed type hypersensitivity and diminution of $\mathrm{T}$ cell activation has been observed in in vitro studies by blocking these channels. The venom of three Brazilian scorpions such as $T$. stigmurus, , $T$. bahiensis and T. serrulatus contained butantoxin that inhibit the proliferation of $\mathrm{T}$ cells and IL-2 production by reversibly blocking potassium channels (Shieh et al., 2000; Tenenholz et al., 2000; Holaday et al., 2000).

\subsection{Calcium Channel Toxins}

To regulate various cellular functions such as gene expression, intracellular metabolism, neurotransmitter release and cellular excitability, $\mathrm{Ca}^{2+}$ ion is crucial. The $\mathrm{Ca}^{2+}$ channels are widely distributed in the body such as endocrine cells, smooth muscle, skeletal muscles neuron and heart muscle. Numerous peptides present in the scorpion venom affect these ion channels activities and modulate their functional properties. These peptides have unlike pharmacological and physiological properties. Various studies have been shown that scorpion toxins are used in protein engineering scaffolds, cancer treatment, vaccines and insecticides (Catterall, 1992).

\section{Activity of Scorpion's Venoms}

The scorpion's venom has various neurotoxic, hemolytic and muscular effects in humans. Furthermore, anti-bacterial, anti-fungal, anti-insect, anti-tumor, analgesic, cytotoxic and apoptotic effects of scorpion venoms on various organism have been reported (Diniz, 1978; Willems et al., 2002). In human, it is used for the treatment of rheumatism, pancreatitis, skin cancer, breast cancer, prostrate tumor, kidney tumor, male impotency, brain tumor, leukemia, epilepsy, HIV, tetanus, cardiovascular diseases, subcutaneous nodules and acute and chronic convulsions (Chen et al., 2012).

\section{Mode of Action}

The membrane disrupting peptides affect net movement of ions that leads to fatal depolarization. It creates cellular pores, causing cellular content to leak out. These peptides induce hydrolases which degrade cell membrane. It also disturbs membrane functions by scrambling the distribution of lipids (Tossi et al., 2000).

\subsection{Scorpion Antivenin}

Pain following scorpion bite is very severe and that is why it is worth talking about. Systemic opioids and antihistamines have been used in combination with locally injected lidocaine. However, when lidocaine fails to relieve pain, alternative therapy must be sought. Chloroquine, a quinoline derivative, which can disrupt neural transmission, was tried successfully in the case reported. Two milliliters of the agent was injected around the sting site and near the digital 
nerves. Pain relief was reported 3 minutes later and was sustained for 24 hours (Amucheazi and Umeh, 2012). Among all poisonous species of scorpions, red scorpion (Mesobuthus tamulus) is the most lethal. Scorpion venom is a potent sodium channel activator and envenoming by Mesobub jthus tamulus results in sudden pouring of endogenous catecholamines into circulation due to the autonomic storm evoked by delayed inactivation of neuronal sodium channels Vomiting, profuse sweating, priapism in males and cold extremities precede the development of severe cardiovascular manifestations Clinical manifestations depend on the dose of venom, season of sting and time elapsed between sting and hospitalization Alpha-receptor stimulations play a major role in the pathogenesis of acute pulmonary edema Scorpion antivenin did not reverse and prevent the cardiovascular morbidity and mortality due to envenoming by red scorpion sting (Vasconcelos et al., 2005; Bawaskar and Bawaskar, 2012).

\subsection{Scorpion Toxin and Cancer}

Cancer has a major impact on human health and important public health problem worldwide. Since it has a high morbidity and mortality worldwide, there is an urgent need to find better treatment. Treatment modalities towards the cancer comprise radiation therapy, surgery, chemotherapy, immunotherapy and hormonal therapy. Out of the therapies being used for treatment, chemotherapy remains the predominant option. However, patients often develop resistance to chemotherapeutics acquired by tumors. In addition, chemotherapeutics used in systemic administration often lead to serious side effects. This has led to the development of new strategies to achieve effectiveness against cancer (Baskar et al., 2012).

\subsection{Scorpion Toxin and Glioma}

Glioma is rapidly spreading and a highly invasive form of brain cancer that is resistant to medical and surgical treatment. It is a sort of tumor in the spine or brain.. The most common site of gliomas is the brain. As it arises from glial cells therefore, called glioma. The scorpion toxins are used to treat cancer patients by injecting fluorescent scorpion toxin into cancerous tissue to show tumor boundaries. BmK AGAP is sodium channel-specific neurotoxins from Buthus martensii Karsch. BmK AGAP toxin inhibited growth of glioma cells by inducing apoptosis. In the venom of the death stalker scorpion (Leiurus quinquestriatus) is found a 36-amino acid peptide called Chlorotoxin, which blocks small-conductance chloride channels. Chlorotoxin is not toxic to mammalian systems but toxic to insects. Glioma cells have been shown to express a glioma-specific chloride ion channel (GCC) that is sensitive to chlorotoxin (CTX). Chlorotoxin is specifically bind to glioma cells. Cholorotoxin may serve as glioma-specific markers with diagnostic and therapeutic potential. Cholorotoxin helps to early detection of glioma cancer cells could save lives (Veiseh et al., 2007; Kesavan et al., 2010).

\subsection{Scorpion Toxin and Leukaemia}

Leukemia is a kind of cancer of the bone marrow or blood described by an abnormal rise of immature white blood cells called "blasts". From the Indian scorpion (H. bengalensis) a high molecular weight protein called bengaline is isolated. Bengalin possessed apoptogenic, 
cytotoxic and antiproliferative activity against K562 (chronic myelogenous leukemia) and human leukemic cells U937 (histiocytic lymphoma). Bengalin provide a putative molecular mechanism for their anticancer effect on human leukemic cells mediated by mitochondrial death cascade (Hayden et al., 2006).

\subsection{Scorpion Toxin and Breast Cancer}

Breast cancer is a cancer originating from breast tissue; most commonly from the inner lining of milk ducts it has become common in developing and developed countries. Alarming increase in this disease as a leading cause of death in and breast cancer is the second only to lung cancer as a cause of death from cancer among women. Despite the significant improvements in the management of breast cancer, the survival rate is not more than $20 \%$ $25 \%$. Most common death in breast cancer patients is due to metastatic spread of cancer cells which invade into angiogenic blood vessels growing into the tumor. Breast cancer may be invasive or noninvasive. Invasive means it has spread from the milk duct or lobule to other tissues in the breast. Noninvasive means it has not yet invaded other breast tissue. A hyaluronidase(BmHYA1), was purified from the venom of Chinese red scorpion (Buthus martensi). The human breast cancer cell line of MDA-MB-231 is an aggressive cancer cell line that supposedly contains much hyaluronan. Hyaluronidase reduces human breast cancer. It may provide a new class of anti-cancer therapeutics and without toxic side effects (Feng et al., 2008; Sariego, 2010).

\subsection{Scorpion Toxin and Brain Tumor}

An intracranial solid neoplasm is a brain tumor. Within the central spinal canal or brain, tumor is the abnormal growth of cells. The scorpion venom peptide, chlorotoxin shows promise as an imaging agent for brain surgery. Chlorotoxin is an example of an elaborated cystine knot. Cystine knot contains an extra disulfide bond. Chlorotoxin is specifically bind to brain tumor cells. Chlorotoxin is conjugated with fluorescent dye can be used as a 'tumor paint' to delineate the margins of brain tumors and hence facilitate their surgical removal. This selective cancer cell targeting probably occurs via binding to the extracellular matrix protein, which is overexpressed in brain cancer cells. Cholorotoxin may serve as brain tumor-specific markers with diagnostic and therapeutic potential (Biswas et al., 2010).

\subsection{Scorpion Venom and Prostate Cancer}

Prostate cancer is the major cause of death in men and at present, is the second leading cause of cancer deaths in North American men. It has been revealed that polypeptide extract from the scorpion venom PESV is potent against androgen independent-prostate cancer cell lines. Hormone refractory prostate cancer (HRPC) remained a challenge but the finding of new promising agent is important against androgen independent prostate cancer. A polypeptide extract from scorpion venom (PESV) has been isolated from Buthus martensi Karsch (Bmk). PEVS is a peptide with 50-60 amino acids and has anti proliferative, cytotoxic and apoptosis-induced activities against Human Umbilical Vein endothelial Cell (HUVEC), inhibition of neovascularization, suppression of tumor growth of S180 sarcoma and H22 hepatocelluar carcinoma in mice (Zhang et al., 2009). 
6.8 Scorpion Toxin and Skin, Lung, Cervical, Esophageal and Colon Cancer

For early detection of colon, esophageal, cervical, lungs, and skin cancer, Cholorotoxin is a noninvasive screening tool. Cholorotoxin is conjugated with iron oxide nano particles through a polyethylene glycol linker could successfully attach to both drug and targeting ligands. The target nanoparticles demonstrated preferential accumulation and increased cytotoxicity in tumor cells. Further, in invivo models these nanoparticles were retained within the tumors. It was suggested that this multifunctional nanoparticle system may find potential application in cancer diagnosis and treatment (Sun et al., 2008).

\subsection{Scorpion Venom and Human Lung Adenocarcinoma}

Scorpion venom contains different enzymes like, proteolytic enzymes, alkaline phosphatase, acetylcholinesterase and phospholipase A2 enzymes having potent gelatinolytic and cytotoxic activities. The proteolytic enzymes in venom can cause gangrene, hemolysis and necrosis. In the treatment of various cancers, identifications of these proteases are very crucial. Considerable decrease in cancerous cell lines has been reported when proteases from Mesobuthus gibbosus is applied on the human lung adenocarcenoma (A549) cell lines (Pessini et al., 2001). So against human lung adenocarcinoma, these peptides have a very potent gelatinolytic and cytotoxic activities.

\subsection{Scorpion Venom and Melanoma}

Peptide TRAIL (TNF-related apoptosis-inducing ligand) obtained from scorpion venom is used to induce apoptosis in melanoma cells. This peptide target only cancer cells while normal cells remain unaffected. TRAIL in melanoma cells initiate proapoptotic Bcl-2 proteins and caspases while down regulates TRAIL receptors. TRAIL causes mitochondrial outer membrane permeabilization and depolarization of the mitochondrial membrane potential, resulting in the release of mitochondrial factors such as, SMAC (second mitochondria-derived activator of caspases), AIF (apoptosis-inducing factor) and cytochrome c which ultimately inhibits melanoma cells proliferation and induces its death by apoptosis (Norberg et al., 2010; Quast et al., 2012).

\section{Conclusion}

It has been found that, scorpion venoms contained a lot of therapeutically crucial novel peptides which possess apoptogenic, cytotoxic and anti-proliferative activities against different types of cancers. Now a day to visualize the boundaries between cancerous tissues and normal tissues florescent labeled scorpion venom peptides are used. Still a lot of peptides in scorpion venom are not identified. Further studies are needed to identify therapeutically crucial peptides in scorpion venom.

\section{References}

Ammar, A., \& Qosay, A. (2014). Scorpion venom peptides with no disulfide bridges: A review. Peptides, 51, 35-45. http://dx.doi.org/10.1016/j.peptides.2013.10.021

Amucheazi, Ao., \& Umeh, BU. (2012). Scorpion sting pain: Which way to treat? Nigerian 
Journal of Clinical Practice, 5(1), 93-94. http://dx.doi.org/10.4103/1119-3077.94107

Baskar, R. Lee, KA., \& Yeo, R. (2012). Cancer and radiation therapy: current advances and future directions. International Journal of Medial Sciences, 9, 193-9.

Bawaskar, HS., \& Bawaskar, HP. (2012). Scorpion Sting: Update. J. Assoc. Physicians India, 60, 46-53. http://dx.doi.org/10.7150/ijms.3635

Biswas, A. Gomes, A. Sengupta, J. Datta, P. Singha, S. Dasgupta, AK., \& Gomes, A. (2012). Nanoparticle-conjugated animal venom-toxins and their possible therapeutic potential. Venom Research, 3, 15-21.

Catterall, WA. (1992). Cellular and molecular biology of voltage-gated sodium channels. Physiol Rev, 72(4), 15-48.

Cestèle, S., \& Catterall, WA. (2000). Molecular mechanisms of neurotoxin action on $\begin{array}{llll}\text { voltage-gated } \quad \text { sodium } \quad \text { channels. } & \text { Biochimie, } & \text { 82(9), }\end{array}$ http://dx.doi.org/10.1016/S0300-9084(00)01174-3

Chen, Y. Cao, L. Zhong, M. Zhang, Y., \& Han, C. (2012). Anti-HIV-1 Activity of a new Scorpion Venom Peptide Derivative Kn2-7. PLoS ONE, 7, 34947. http://dx.doi.org/10.1371/journal.pone.0034947

Dehesa-Dàvila, M. Martin, BM. Nobile, M. Prestipino, G., \& Possani, LD. (1994). Isolation of a toxin from Centruroides infamatus infamatus Koch scorpion venom that modifies $\mathrm{Na}+$ permeability on chick dorsal root ganglion cells. Toxicon. 32(12), 1487-93. http://dx.doi.org/10.1016/0041-0101(94)90307-7

Diniz, CR. (1978). Chemical and pharmacological aspects of Tityinae venoms. Handbook of Experimental Pharmacology. Arthropod venoms, 48 (14). Springer, Berlin, 379-394.

Feng, L. Gao, R., \& Gopalakrishnakone, P. (2008). Isolation and characterization of a hyaluronidase from the venom of Chinese red scorpion Buthus martensi. Comp Biochem Physiol C Toxicol Pharmacol, 148, 250-257. http://dx.doi.org/10.1016/j.cbpc.2008.06.003

Hayden, MS. West, AP., \& Ghosh, S. (2006). NF-кB and the immune response. Oncogene, 25, 6758-6780. http://dx.doi.org/10.1038/sj.onc.1209943

Holaday, SK. Martin, BM. Fletcher, PL., \& Krishna, NR. (2000). NMR solution structure of butantoxin. Arch Biochem Biophys, 1(379), 18-27. http://dx.doi.org/10.1006/abbi.2000.1858

Jeyaprakash, J., \& Hoy, MA. (2009). First divergence time estimate of spiders, scorpions,mites and ticks (subphylum: Chelicerata) inferred from mitochondrial phy-logeny. Exp Appl Acarol, 47, 1-18. http://dx.doi.org/10.1007/s10493-008-9203-5

Kesavan, K. Ratliff, J. Johnson, EW. Dahlberg, W. Asara, JM., \& Misra, P. (2010). Annexin A2 is a molecular target for TM601, a peptide with tumor-targeting and anti-angiogenic effects. Biol Chem, 285, 4366-4374. http://dx.doi.org/10.1074/jbc.M109.066092

Michael, ES., \& Victor, F. (2003). High-level systematics and phylogeny of the 
extantscorpions (Scorpiones: Orthosterni). Euscorpius, 11, 1-175.

Norberg E. Orrenius, S., \& Zhivotovsky, B. (2010). Mitochondrial regulation of cell death: Processing of apoptosis-inducing factor (AIF). Biochem Biophy Res Comm, 396, 95-100. http://dx.doi.org/10.1016/j.bbrc.2010.02.163

Park, J. Cho, SY., \& Choi, SJ. (2007). Purification and characterization of hepatic lipase from Todarodes pacificus. BMB reports, 254-258.

Pessini, AC. Takao, TT. Cavalheiro, EC. Vichnewski, W. Sampaio, SV. Giglio, JR., \& Arantes, EC. (2001). A hyaluronidase from Tityus serrulatus scorpion venom: isolation, characterization $\begin{array}{lllll}\text { and inhibition by flavonoids. } & \text { Toxicon, } & 39, & \end{array}$ http://dx.doi.org/10.1016/S0041-0101(01)00122-2

Possani, LD. Becerril, B. Delepierre, M., \& Tytgat, J. (1999). Scorpion toxins specific for Na+channels. uropean Journal of Biochemistery, 264(2), 287-300.

Possani, LD. Merino, E. Corona, M. Bolivar, F., \& Becerril, B. (2000). Peptides and genes coding for scorpion toxins that affect ion-channels. Biochimie, 82(9), 861-8. http://dx.doi.org/10.1016/S0300-9084(00)01167-6

Quast, SA. Berger, A. Buttstädt, N. Friebel, K., \& Schönherr, R. (2012). General Sensitization of Melanoma Cells for TRAIL-Induced Apoptosis by the Potassium Channel Inhibitor TRAM-34 Depends on Release of SMAC. PLoS ONE, 7, 39290. http://dx.doi.org/10.1371/journal.pone.0039290

Ruming, Z. Yibao, M. Yawen, H. Zhiyong, D. Yingliang, W. Zhijian, C., \& Wenxin, L. (2010). Comparative venom gland transcriptome analysis of the scorpion Lychas mucronatus reveals interaspecific toxic gene diversity and new venomous components. BMC Genomics, 11, 1-15.

Sariego, J. (2010). Breast cancer in the young patient. The American surgeon, 76, 1397-1401.

Shieh, CC. Coghlan, M. Sullivan, JP., \& Gopalakrishnan, M. (2000). Potassium channels: molecular defects, diseases, and therapeutic opportunities. Pharmacol Rev, 52(4), 557-94.

Sun, C. Stephen, Z. Veiseh, O. Harisen, S. Lee, D. Ellenbogen, RG. Olson, J., \& Zhang, M. (2008). Tumor targeted drug delivery and MRI contrast enhancement by chlorotoxin conjugated iron oxide nanoparticle. Nanomed, $3, \quad 495$. http://dx.doi.org/10.2217/17435889.3.4.495

Tenenholz, TC. Klenk, KC. Matteson, DR. Blaustein, MP., \& Weber, DJ. (2000). Structural determinants of scorpion toxin affinity: the charybdotoxin (alpha-KTX) family of $\mathrm{K}(+)$-channel blocking peptides. Rev Physiol Biochem Pharmacol. 140, 135-85. http://dx.doi.org/10.1007/BFb0035552

Tossi, A. Sandri, L., \& Giangaspero, A. (2000). Amphipathic, a-helical antimicrobial peptides. Biopolymers, 55 , 4-30. http://dx.doi.org/10.1002/1097-0282(2000)55:1<4::AID-BIP30>3.0.CO;2-M

Vasconcelos, F. Lanchote, VL. Bendhack, LM. Giglio, JR. Sampaio, SV., \& Arantes, EC. 
(2005). Effects of voltage-gated $\mathrm{Na}+$ channel toxins from Tityus serrulatus venom on rat arterial blood pressure and plasma catecholamines. Comp Biochem Physiol C Toxicol Pharmacol, 141, 85-92. http://dx.doi.org/10.1016/j.cca.2005.05.012

Veiseh, M. Gabikian, P., \& Bahrami, SB. (2007). Tumor paint: a cholorotoxin: L Cy5.5 bioconjugate for interaoperative visualization of cancer foci. Cancer Research, 67, 6882-8. http://dx.doi.org/10.1158/0008-5472.CAN-06-3948

Willems, J. Noppe, W. Moerman, L. Van der, WJ., \& Verdonck, F. (2002). Cationic peptides from scorpion venom can stimulate and inhibit polymorphonuclear granulocytes. Toxicon, 40, 1679.

Yu, FH., \& Catterall, WA. (2003). Overview of the voltage-gated sodium channel family. Genome Biol. 4(3), 207. http://dx.doi.org/10.1186/gb-2003-4-3-207

Zhang, YY. Wu, LC. Wang, ZP. Wang, ZX. Jia, Q. Jiang, GS., \& Zhang, W D. (2009). Anti-proliferation Effect of Polypeptide Extracted from Scorpion Venom on Human Prostate Cancer Cells in vitro. Clin Med Res, 1, 24-31.

\section{Copyright Disclaimer}

Copyright for this article is retained by the author(s), with first publication rights granted to the journal.

This is an open-access article distributed under the terms and conditions of the Creative Commons Attribution license (http://creativecommons.org/licenses/by/3.0/). 